\title{
Anticipating the clinical adoption of regenerative medicine: building institutional readiness in the UK
}

\author{
John Gardner*,1, Andrew Webster² \& Jacqueline Barry ${ }^{3}$ \\ ${ }^{1}$ School of Social Sciences, Monash University, Clayton Campus, W414 Menzies Building, 20 Chancellors Walk, \\ Melbourne, Australia \\ ${ }^{2}$ Department of Sociology, Science \& Technology Studies Unit, Wentworth College, University of York, York YO10 5DD, UK \\ ${ }^{3}$ Cell \& Gene Therapy Catapult, Guy's Hospital, 12th Floor Tower Wing, Great Maze Pond, London SE1 9RT, UK \\ * Author for correspondence: Tel.: john.gardner@monash.edu
}

This perspective paper examines the challenges of implementing regenerative medicine (RM) therapies within hospitals and clinics. Drawing on recent work in the social sciences, the paper highlights dynamics within existing healthcare systems that will present both hindrances and affordances for the implementation of new RM technologies within hospitals and clinics. The paper argues that identifying suitable locations for cell- and gene-therapy treatment centers requires an assessment of their institutional readiness for RM. Some provisional criteria for assessing institutional readiness are outlined, and the paper will suggest that it is necessary to begin developing a program for the phased introduction of RM in the longer term.

First draft submitted: 22 August 2017; Accepted for publication: 2 November 2017; Published online: 23 January 2018

Keywords: commissioning $\bullet$ GMP $\bullet$ hospitals $\bullet$ institutional readiness $\bullet$ National Health Service $\bullet$ risk-sharing • technology adoption

Regenerative medicine (RM) therapies, particularly those that are commonly referred to as advanced cell and gene therapies, are in many ways significantly different from existing, conventional therapeutic products and techniques [1]. Cell, tissue or gene-based technologies have the potential to provide therapeutic relief for a range of disorders for which there is currently severe unmet clinical need [2], but the sensitivity and complexity of these technologies presents a range of innovation challenges [3], and commentators have suggested that promising RM technologies are particularly susceptible to the 'valley of death' [4]. Many of these challenges relate to upscaling and manufacturing, regulatory requirements, reimbursement and commissioning [5]. These have been well characterized in recent reviews of the RM field [6], and government-supported initiatives such as the UK's Cell and Gene Therapy Catapult have been launched to mitigate these and facilitate commercialization [7]. Recent reports, however, have identified an additional area of concern: the clinical adoption of RM therapies within existing healthcare systems $[8,9]$. Hospitals and clinics within contemporary healthcare systems have developed systems to accommodate drug- and device-based therapies and surgical interventions, and they may, then, be poorly suited to implementing cell-, tissueand gene-based treatments. There is, in other words, a degree of incommensurability between existing healthcare providers and the exigencies of providing RM therapies [10].

A consequence of this mismatch is that potential investors have difficulties envisaging a clear pathway to commercial and clinical success [11]. This uncertainty represents a risk to the momentum that currently characterizes RM in the UK, Canada, various US states and elsewhere. Hence, while the majority of promising RM therapies are still in the early phases of clinical development [12], commentators have argued that it is necessary to address the potential challenges of clinical delivery in the immediate future $[8,9,11]$. In this vein, this paper examines the challenges of implementing RM technologies within existing systems of delivery, and it offers some guiding reflections on how such challenges may responsibly be managed. RM represents a diverse range of technologies and techniques, many of which can be characterized as disruptive innovations [13]. The ecosystem of biomedical innovation is being redrawn as policy makers and other stakeholders attempt to facilitate the translation of promising developments in the lab into 
useful, cost-effective clinical tools: new regulatory pathways are being forged, novel interdisciplinary collaborations are being encouraged and new innovation-facilitating agencies have been established [14]. Healthcare providers are also implicated in these changes as new clinical delivery infrastructures will be required. The considerable financial strain experienced by providers and healthcare systems in many countries, however, could hamper the required transformations. It is necessary, then, to anticipate likely challenges and tensions of implementation, and to identify potential opportunities, so that resources and expertise can be responsibly deployed. Hence, in the following section, this paper will provide a brief overview of recent research in the social sciences on what is often referred to as the problem of 'technology adoption' in healthcare. This body of work highlights some of the general dynamics within existing healthcare delivery infrastructures that present both hindrances and affordances for the implementation of new technologies. These are highly relevant for RM, but as the paper will illustrate, promising RM therapies present an additional set of challenges. In the section 'Advanced Therapy Treatment Centers', this paper will provide a brief overview of recent proposals to establish specialist cell and gene therapy treatment centers within the UK. In order to prompt and contribute to discussion on the substantive dimensions of these centers, the paper will identify important precedents and opportunities within existing healthcare arrangements. The paper will argue that identifying suitable locations for cell and gene therapy treatment centers will require an assessment of their 'institutional readiness' (IR) for RM. Additionally, the paper will specify some relevant criteria for assessing IR. In the final section, the paper will propose that the longer-term implementation of RM therapies within the healthcare system should occur in three sequential phases. A preliminary sketch of the activities required at each phase to ensure that the healthcare system is responsibly transformed will be provided.

\section{The challenge of technology adoption in healthcare}

Conventional and now largely outdated understandings of innovation as a linear process have tended to portray the adoption of new technologies within contexts as a relatively simple process. This is perhaps most apparent in the 'technology readiness' framework, for example [15], in which at the end of the innovation process, a fully developed and discrete technology or system is straightforwardly implemented in relevant contexts [16]. Within the last decade, however, there has been a widespread recognition among policy makers and the biomedical community that technology adoption can be a problematic and disruptive process that necessitates active engagement [17]. This interest in technology adoption has been prompted by a confluence of factors which include a political concern with variations in service quality within healthcare systems, high-profile technology adoption failures and perhaps most notably, the emerging focus on facilitating translational medicine. Much of the discourse surrounding translational medicine and accelerating access to promising new treatments emphasizes the importance of engaging end users (front-line clinicians) in upstream innovation processes, so that the new technology, technique or system will be better configured for actual clinical use, for example [9,18].

This policy interest in technology adoption has prompted social science research into specific adoption processes in medicine involving a range of innovations such as IT systems, surgical procedures, diagnostics and medical devices. The general finding from this literature is that healthcare contexts are characterized by considerable complexity and heterogeneity [19]: any given healthcare provider is constituted by often obdurate infrastructures and routines, multiple professions with sometimes conflicting viewpoints and interests, funding pressures and resource constraints, all of which can complicate the uptake of new technologies and practices [17]. The more specific findings of this body of work are highly relevant for the implementation of RM technologies.

First, the adoption of a technology, practice or system will be severely hindered if it does not align with professional and institutional interests and values. For example, the uptake of telemedicine within psychiatry (which was much championed in UK healthcare policy) was resisted by front-line health professionals who felt that it inhibited their ability to provide attentive and effective care [20]. The importance of institutional interests is illustrated with the adoption of a robotic surgical system for prostatectomy by health providers in many parts of the world [21,22]. In the UK, the robotic system has not been recommended by NICE for prostatectomy because as yet there are insufficient data that it offers meaningful clinical or cost advantages over conventional procedures [23]. Despite this, National Health Service (NHS) hospitals - as with other hospitals in Europe - have enthusiastically embraced the technology and have creatively sourced funding to purchase and maintain the system. The principal reason for this is that the high profile of the system as being 'high-tech' and 'futuristic' helped hospitals to publicly position themselves as being at the forefront of medical innovation $[21,22]$. The robotic system, in other words, had an identity that aligned with institutional interests. 
Second, social science studies have also illustrated that the distinction between cost-effectiveness and affordability is highly relevant to adoption. This is illustrated by Celution ${ }^{\circledR}$ System within the UK, a cell preparation device that is used in soft tissue repair such as partial breast reconstruction following cancer treatments (The Celution System is manufactured by the San Diego-based Cytori Therapeutics, Inc. [CA, USA]). The system was deemed cost-effective by the NHS Technology Adoption Centre in 2011 [24], and surgeons using the device have found it to be highly useful, but its uptake in the NHS has been limited. One reason proffered for this (in addition to some regulatory uncertainty surrounding the device) was that it has a relatively high upfront cost and is therefore perceived by NHS trusts as unaffordable [25]. The payment structures and fixed budgets that characterize many universal healthcare systems such as the UK's NHS mean that large upfront costs cannot easily be offset by overall savings in the longer term [26] although this may be possible for healthcare systems based on national or private insurance. Successful technology adoption is, then, dependent on a good business case that accounts for local budgeting and finance mechanisms.

And third, the adoption of technology may also be hindered by differences in opinion among health professionals over what counts as 'evidence'. As Madden has illustrated, clinicians in some specialties are often more likely to be influenced by the testimony of their colleagues than evidenced-based medicine [27]. Similarly, clinicians pioneering and advocating the use of deep-brain stimulation as a treatment for dystonia in children are having to challenge existing clinical assessment measures and promote the use of what they believe to be more meaningful assessments, which provide better proof of the therapy's effectiveness [28,29]. Wider adoption of deep-brain stimulation in pediatric neurology will depend on their ability to redefine what 'counts as evidence'.

These examples illustrate that the demonstration of a technology's cost-effectiveness and clinical utility (e.g., via a clinical trial) will not guarantee its successful adoption; other social and organizational factors, such as professional interests, institutional prestige and budgetary models, will constrain or enable adoption practices. More generally, these examples illustrate that a successful, innovative technology, practice or procedure in medicine is not a discrete thing in itself. Rather, it is an institutionally sanctioned 'change in the structure of delivery services' [30]. Implementation scholars such as May, Greenhalgh et al. have explored the dynamics and practices that are required to bring about such change [31-34]. It requires, May argues, that the innovative technology, practice or procedure is actively embedded within a context (itself never static) via the ongoing work of creative agents (such as health professionals). This requires collective effort from diverse agents (such as front-line health professionals, administrators, managers) who need to be actively enrolled in the project: workloads and goals need to be coordinated and aligned with the requirements and opportunities presented by the new technology, practice or procedure [30,35]. May argues that the formation of systems for monitoring and evaluation are especially important for successful adoption, as they permit the collective, reflective appreciation of the innovation and thus ongoing re-enrollment of key stakeholders. These dynamics identified by May are important elements of what we will describe in a later section as IR.

\section{Specific adoption challenges relating to RM}

The examples from social science research discussed above highlight adoption dynamics that are highly relevant for RM. Many promising RM technologies on the horizon, for example, are likely to be high cost and hence possibly unaffordable within some existing payment arrangements [36,37]. Institutional interests are also likely to be important: existing studies have illustrated that some organizations have strategically positioned themselves as 'pioneers' in RM [25]. And, uncertainties surrounding evidence of clinical and cost-effectiveness have already hindered the adoption of some advanced therapies (specifically ChondroCelect ${ }^{\circledR}$ and MACI, competing products for treating cartilage defects) [25,38]. The complexity and novelty of RM products and techniques, however, presents an additional set of more specific adoption challenges.

First, specialist infrastructure and expertise are required to supply (transport and store) RM products, and to prepare products at the clinic. Some products, for example, will require cryogenic cold-chain transportation and specialist-thawing systems at the point of clinical delivery. Appropriate quality-assurance (QA) mechanisms will also be needed. Many existing hospitals within the UK's NHS, for example, lack this infrastructure and expertise [39]. Second, some products (particularly autologous products) will necessitate new manufacturing arrangements, a process of scale-out rather than scale-up. While some allogeneic products will have centralized manufacturing, other products will require new redistributed manufacturing arrangements such as the 'hub and spoke' model. Some products, particularly autologous products, will need to be either partially of fully manufactured near the patient. This will require an onsite, or near-to-site GMP-licensed manufacturing space, linked to any existing Pharmacy Manufacturing Unit or cell laboratory. Such facilities are expensive to run, and adhering to the required 
regulatory guidelines can be onerous. On-site manufacturing will also require expensive bioprocessing equipment with appropriate validation and QA-compliant systems. If manufacturing of advanced cell and gene therapies is to be cost-effective, then automated, modular, closed cell separation and expansion systems will be required. These will represent significant upfront costs, and while there are such systems currently available on the market (such as Miltenyi Biotec's 'CliniMACS Prodigy System'), more innovation in this area is needed. An additional layer of complexity here is the dynamic nature of the highly innovative field of RM. It is likely that after initial introduction, manufacturing processes will be subject to ongoing improvements and therapies will be incrementally adapted and customized. Healthcare settings and regulation will need to be sufficiently flexible for such therapies that may change from year to year. Fourth, it is likely that in some cases a hospital or a clinic will act as a cell or tissue procurement service for a third party such as a commercial manufacturer. This will require complex contract arrangements that allocate responsibilities (such as quality assurance) and liabilities between parties [39].

And fifth, some of the promising payment-by-performance risk-sharing commissioning schemes for RM therapies, in which payment (and financial risk) is shared between partners, will require coordinated data-collection infrastructures at clinical sites, so that payment can be aligned with specific clinical outcomes. Such data infrastructures can be expensive and time-consuming to establish and determining who collects data and tracks patient outcomes often difficult to resolve [40].

The adoption of RM technologies within hospitals and clinics thus presents a range of challenges that relate to supporting infrastructures and skill base, regulatory requirements, commissioning and reimbursement. It has been argued elsewhere, for example [41], that the successful adoption of RM will require the establishment of 'innovation niches': protected, organizational arrangements and technical infrastructures that provide a seed-bed for the product or technique to be nurtured, so that a further evidence based can be generated, and so that logistical arrangements and other supporting systems can be trialed and consolidated [42]. The following section will provide an overview of recent proposals to establish formal innovation niches for RM in the UK, in the form of a network of specialist centers for cell and gene therapy treatments $[9,11]$. There are, it will be argued, important precedents and opportunities for these proposed centers in the existing UK healthcare system.

\section{Advanced therapy treatment centers: precedents \& opportunities}

The Regenerative Medicine Expert Group report (2015) and more recently the Advanced Therapies Manufacturing (ATM) Taskforce Report (2017) have called for the establishment of specialist centers for delivering cell and gene therapies within the UK $[8,11]$. The ATM Taskforce has recommended that $£ 30$ million in new government funding be administered by Innovate UK to establish the centers via a competitive process. This would encourage the consolidation of resources and expertise around designated hospitals that already have extensive experience in developing and trialing RM therapies [11]. Possible candidates are likely to include sites that include hospitals in Edinburgh, Newcastle and London (University College London Hospital, Kings, Guy's and St Thomas' Hospitals, Royal Free Hospital, UK), all of which have made strategic investments in RM, and have access to GMP facilities with expertise in cell, tissue and gene-based product development. It is envisaged that the funding would be used for refurbishing infrastructure rather than the construction of new buildings.

The rationale for establishing the network of centers is that they would provide the necessary stability that would enable the trialing and consolidation of supply chains, data collection infrastructures and the trialing and consolidation of appropriate business models for industrial partners [11]. They would act as test beds or exemplars within the RM field, which could then be extended at a national level and give stakeholders and potential investors a clearer pathway to commercial and clinical success. It is envisaged that the centers would be carefully coordinated to ensuring the sharing of best practice, and the ATM report also argues that the centers would constitute partnerships between NHS organizations and industry: the NHS organizations would provide the clinical expertise and support patient access, while industrial partners would provide manufacturing and logistical expertise [11].

The substantive dimensions of this network of centers, and indeed the criteria according to which competitive funding might be allocated, have yet to be elucidated. In order to prompt discussion on these issues, here we highlight some important precedents and opportunities within existing healthcare arrangements in the UK and elsewhere. The most important are existing hematological services, and particularly the NHS Blood and Transplant (NHSBT) service and the Scottish National Blood Transfusion Service. These represent an important reservoir of infrastructure and expertise for procurement and transportation of cells and tissues, for administering cell-based treatments and for preparing patients [39]. They also represent a vital reservoir of expertise in dealing with Human Tissues Authority, Medicines and Healthcare products Regulatory Agency and EMA regulatory requirements, including those relating 
to GMP licensing. Lowdell and Thomas, for example, provide an account of an existing arrangement at the Royal Free Hospital in which transported cryopreserved materials are received by hematology staff with relevant QA and handling expertise rather than by the hospital pharmacist [39]. Several of the more advanced and highly promising developments in RM, such as gene therapy for severe combined immunodeficiency and chimeric antigen receptor T-cell (CAR-T cell) therapies for blood cancers, have emerged from these services and have significant homologies with routinely offered hematopoietic stem cell transplantations. NHSBT and Scottish National Blood Transfusion Service have also been partners in other projects in RM - a notable example being the NHSBT's collaboration with Videregen on the bioengineered trachea [43]. Existing hematological and transplantation services, therefore, provide an important springboard for establishing specialist cell and gene therapy treatment centers. There will also likely be a role for the national NHS Clinical Research Networks who may, through the National Institute for Health Research, provide a route through which to help embed RM within the NHS more broadly.

Existing risk-sharing schemes for high-cost drugs are also highly relevant for the proposed network of treatment centers. The UK has several such schemes for high-cost oncology drugs and recently a heart drug [44], and in Scotland, some orphan drugs and hemophilia treatments are also funded in this way [45]. Importantly, the integrated electronic patient records system within Scotland allows for 'payment by performance' schemes, in which payments to manufacturers are aligned with clinical outcomes. Similar schemes are used in other European countries, particularly Italy [46]. Most notably, this includes the EMA-approved Strimvelis, a gene therapy for adenosine deaminase severe combined immunodeficiency (ADA-SCID) with a cost of over US $\$ 600,000$ per patient. The manufacturer GSK supplies the treatment with a 'money back guarantee', so that GSK is paid for only those patients who are successfully treated [47]. Such funding arrangements (and the supporting clinical outcome data collection infrastructure they require) provide an important precedent for RM [44], and particularly the proposed advanced therapy treatment centers. Indeed, it is likely that many of the initial therapies offered by these centers will be high cost and targeted for rare indications, much like those treatments that are already supported via 'specialized commissioning'.

Another important (and perhaps less obvious) precedent for implementing highly disruptive RM technologies is the current establishment of the UK Proton Beam Therapy program in the UK [48]. Two proton beam therapy centers are being developed, and the program has involved the development of substantial 'bricks and mortar' infrastructure, new staff training regimes and new patient pathways. The UK government has committed $£ 250$ million to the program [49]. It has required coordination from a range of agencies within the healthcare system, the Department of Health, NHS Foundation Trusts, Health Education England and others. It may be that implementing some of the more disruptive RM therapies will require a similar level of upfront investment and coordination.

\section{The important role of patients \& patient charities}

An additional issue that needs to be considered is the role of patients and patient charities in informing the design of clinical services for RM therapies. Current healthcare policy in the UK, as in many OECD countries, is advocating patient-centered approaches [28], and there is evidence illustrating the benefits of having patient involvement in the organizational design of clinical services [50-52]. There are some particular issues that might warrant patient perspectives when establishing the network of cell and gene therapy treatment centers, and the implementation of RM more generally. These include the geographical distribution of treatment centers. While in the short term it is necessary to consolidate resources at a few specialist centers, in the longer term, when ideally treatments become available for more prevalent indications, it is important to avoid exacerbating already problematic regional inequalities. Patient involvement can also be used to help ensure that the clinical outcome measures used in specialist centers are relevant: do the outcome measures, in other words, capture clinical changes that are important for patients and their families? It is also important to ensure that services have a means of providing appropriate support mechanisms for managing the psychosocial dimensions of illness and treatment. This may mean ensuring that specialist treatment centers have productive links with community health and social services. Such a patient-centered approach recognizes that promising new RM therapies - as with many promising therapies [53] - should be seen as part of a regime of care, rather than as some sort of technological fix.

\section{IR for RM}

Such precedents and opportunities need to be considered when assessing the suitability of potential clinical sites for implementing RM therapies, as do the adoption challenges outlined in earlier sections. These considerations are important elements of what can be defined as the IR of a clinical context. The concept has been developed within 
Box 1. The propositions underpinning the concept of institutional readiness.

- Adoption is the result of active, ongoing work by creative agents (such as front-line clinicians, hospital managers, administrators) who are constrained by bounded rationality and limited resources

- Diverse agents need to be actively enrolled in adopting a technology or technique. This means that their expectations and workloads need to be explicitly aligned

- Adoption requires regular opportunities for relevant staff to engage in reflexive evaluation of the technology and the service. This helps staff to be re-enrolled in the adoption process

\begin{tabular}{|c|c|}
\hline Criteria relating to the regenerative medicine technology or technique & Criteria relating the potential site of clinical delivery \\
\hline Prevalence of target indication & $\begin{array}{l}\text { - Capacity to treat expected patient cohort } \\
\text { - Existing expertise in disease area }\end{array}$ \\
\hline Complexity of intervention & $\begin{array}{l}\text { - Clinical skills for preparing patients and administering treatments } \\
\text { - Opportunities for staff training } \\
\text { - Appropriate infrastructure for administering treatments (e.g., beds) } \\
\text { - Skills in logistical coordination or resources } \\
\text { - Expertise in interdisciplinarity }\end{array}$ \\
\hline Level of patient association/charity support for the therapy & $\begin{array}{l}\text { Opportunities for meaningful patient involvement in organizational design and } \\
\text { service improvement }\end{array}$ \\
\hline Perceptions of technology/technique, for example, does it have a high profile? & $\begin{array}{l}\text { - Goal alignment of front clinicians, administrators, managers and other actors } \\
\text { - Flexibility for aligning work schedules }\end{array}$ \\
\hline $\begin{array}{l}\text { Place and mode of manufacturing: centralized manufacturing? Redistributed } \\
\text { manufacturing (i.e., hub and spoke and/or hospital-based)? }\end{array}$ & $\begin{array}{l}\text { - Access to GMP-licensed facility (and associated GMP expertise) } \\
\text { - Access to and capacity for appropriate bioprocessing systems } \\
\text { - Appropriately trained qualified persons and appropriate quality assurance staff } \\
\text { and systems }\end{array}$ \\
\hline Can costs and clinical outcomes be reliably monitored? & $\begin{array}{l}\text { - Capacity and resource for data-collection infrastructures for monitoring outcomes } \\
\text { - Allocated time for monitoring and for stakeholders to engage in collective } \\
\text { evaluation }\end{array}$ \\
\hline Quality of supporting evidence of clinical utility and cost-effectiveness & Agreement among stakeholders on what constitutes 'evidence' of success \\
\hline Cost & $\begin{array}{l}\text { Ability to secure appropriate funding (via established commissioning structures or } \\
\text { charitable assistance) }\end{array}$ \\
\hline
\end{tabular}

the REGenableMED project, and is based on systematic study of the political and social dimensions of innovation in RM. Specifically, IR within healthcare can be defined as:

"Whether, and if so, how far, an organization needs to adapt to embrace a new technology".

The IR concept is thus premised on the now commonly held assumption that technology adoption is a problematic aspect of the innovation process, rather than being a straightforward deployment of a fully developed product or practice. Drawing on May's and Greenhalgh et al.'s analyses of technology adoption and innovation in healthcare $[30,31,35,54]$, it is based on the propositions outlined in Box 1 .

The value of this approach is that it points to those processes and contexts that shape technology (clinical) adoption, and so how novel organizational forms, such as the advanced therapy treatment centers can be configured to adopt RM manufacture and implementation most efficiently. IR can thus be used as an analytical frame for examining potential clinical sites for the proposed network of cell and gene therapy centers, and indeed for the longer term (and hopefully more widespread) implementation of RM technologies within the healthcare system.

In light of the specific adoption challenges related to RM and the precedents and opportunities noted above, Table 1 provides an overview of relevant general criteria for assessing IR for specific RM technologies and techniques. Given that RM represents a diverse field of technologies and techniques requiring vastly different skill sets and supporting infrastructures, the IR of a clinical site will likely differ substantially for any given technology or technique. Additionally, some criteria, such as 'quality of supporting evidence of clinical utility and cost-effectiveness', relate more to the technology or technique - these are listed in the left column. Other criteria, such as 'capacity to treat expected patient cohort', relate more to the potential site of adoption - these are presented on the right column.

The criteria listed traverse the regulatory, commissioning and technological dimensions of technology adoption. Some of the criteria relate to any disruptive therapeutic innovation. These include the site's existing expertise in specific disease areas; its capacity to treat an expected disease cohort; and the ability to secure appropriate funding (via established commissioning structures or charitable assistance). Many of the criteria are likely to be specific to 
advanced cell and gene therapies, such access to a GMP-licensed facility, access to appropriate bioprocessing systems and necessary skill sets, and appropriately qualified persons and quality assurance mechanisms. In regard to skills, recent work [55] has shown that there is an inadequate supply of technicians in the area, and especially of those who have specialist skills in regard to manufacturing ATMPs. Some of the criteria in Table 1 may be less obvious, but are, in light of the arguments presented above, just as necessary for ensuring successful adoption. These include the strategic objectives of the organization, the opportunities for meaningful patient involvement in organizational design and service improvement, and time for relevant staff to engage in monitoring and collective evaluation.

The list of criteria serves as a useful reminder that an RM technology's market approval and the demonstration of its clinical- and cost-effectiveness are not, on their own, sufficient to guarantee its adoption: there is a diversity of challenges that need to be anticipated and managed. The list, then, can be used to identify specific aspects of a potential clinical site that require targeted investment or management to improve its 'readiness' for RM. Importantly, the list as it is presented here should be seen as highly provisional. As the RM field unfolds, and further challenges and opportunities are specified in greater depth, new IR criteria are likely to be identified

\section{Conclusion}

$\mathrm{RM}$ is championed as having the potential to transform healthcare. The realization of its clinical and economic potential, however, requires initiatives that identify and mitigate various innovation challenges, particularly, as this paper has argued, those relating to the adoption of RM therapies within clinical delivery contexts such as hospitals and clinics. As previous social science studies of adoption processes in healthcare have illustrated, these challenges are diverse and relate to regulation, commissioning and funding, logistical and manufacturing requirements, skill base and expertise, and professional and institutional interests. There are, as this paper has argued, useful opportunities for establishing the proposed network of advanced therapy treatment centers (or innovation niches): existing risksharing schemes and the proton beam therapy program are important precedents, and existing hematological and transplant services represent a valuable 'spring-board' for the proposed centers. It is also necessary to ensure that patient groups are provided with opportunities to meaningfully contribute to the organizational design and service improvement of RM therapy providers. In light of anticipated adoption challenges and existing precedents and opportunities, this paper has presented a provisional list of criteria for assessing the IR of potential clinical sites for delivering an RM technology or technique.

\section{Future perspective: phasing the implementation of RM}

Preparing a fuller, more detailed list of IR criteria should be the first step in the initial phase preparing healthcare systems for the implementation of RM therapies. Given the degree of incommensurability between existing healthcare delivery infrastructures and RM technologies, and given that most promising developments in RM are still many years away (if not decades) from receiving marketing authorization, we suggest that it is necessary to plan the long-term implementation of RM over several phases. In the UK, 'Phase I' would involve the identification and establishment of the network of advanced therapy treatment centers, using the criteria of IR. This would involve horizon scanning to identify which specific therapies are likely to receive marketing authorization and positive assessments from Health Technology Assessment agencies (e.g., NICE). Almost certainly, these are likely to be treatments for relatively small patient groups, or, if larger patient cohorts are envisaged, based on trialing via a performance-based risk assessment over time. It would also require keeping abreast of developments in bioprocessing and logistics technologies for which clinical sites will need to be suitably prepared. Ideally, during Phase I, the network of treatment centers will provide the stability necessary for consolidating supply chain and manufacturing infrastructures and other supporting technologies, the development and testing of business models, and ultimately encourage further investment in the field as a whole. Meanwhile, constant horizon scanning will be necessary to identify promising RM therapies on the 'near horizon'.

Phase II will involve preparing the healthcare system for the more widespread implementation of RM. It will begin when horizon scanning has identified promising therapies on the near horizon that cannot be delivered solely in the network of already-established advanced therapy treatment centers, perhaps due to the prevalence of the indication. An example of this might be a cell therapy for Parkinson's, although such a therapy is likely to be many years away. Ideally, Phase II would involve the application of the IR analysis: to determine the relative impact of institutional change at the advanced therapy treatment centers and how this varies by disease area; and to then deploy the approach to envisage the scale of change needed for novel therapies, in order to move to a much higher order of magnitude in terms of availability. This would entail determining the degree to which systemic changes 
in the healthcare system - a 'trans-IR' - are needed. It is important that a range of stakeholders are involved in these deliberations, notably: relevant patient groups and associations, industry representatives, other experts in the field such as the Cell and Gene Therapy Catapult, the Department of Health, Health Education England, Commissioning agencies (such as NICE or Clinical Commissioning Groups) and front-line clinicians and other staff from NHS foundation trusts. Phase III would begin once the therapy has received a positive health technology assessment (or has been placed on the list of highly specialized services for specialized commissioning). It would entail the actual establishment of a wider array of RM therapy providers, and the implementation of the therapy within these providers. This would require articulating RM with other concurrent developments in biomedical innovation and its deployment, such as large-scale data collection, precision medicine and new (early) diagnostics.

Establishing a program for the phased implementation of RM may help to provide further confidence among potential investors. Importantly, the careful, well-planned phasing-in of RM technologies will ensure that scarce resources are responsibly deployed, that new clinical services provide comprehensive care to patients and their families, and that already much-stressed healthcare systems are not subjected to unnecessary disruption. There are good reasons to think that the UK in particular is well prepared for such a responsible implementation of RM: it has active, well-informed patient charities and associations; it has world-leading hospitals with a commitment to RM; it has extensive expertise in regulation and commissioning and bioprocessing (The Cell and Gene Therapy Catapult being a good example of this); there is a commitment to exploring alternative reimbursement and commissioning

\section{Executive summary}

- Recent reports have identified the implementation of regenerative medicine (RM) therapies within existing healthcare delivery systems as a major challenge.

- Hospitals and clinics are structured to provide drug and device-based therapies and surgical interventions, and may be poorly suited to delivering cell- and gene-based therapies.

- Proactively addressing implementation/adoption challenges will facilitate confidence in the RM field as a whole.

The challenge of technology adoption in healthcare

- Obdurate infrastructures and routines, multiple professions with conflicting viewpoints, funding pressures and resource constrains complicate the uptake of new technologies and practices within hospitals.

- Case studies illustrate that proof of clinical and cost-effectiveness are not sufficient to guarantee a medical technology's adoption.

- RM presents specific challenges relating to logistics and manufacturing requirements, quality assurance, clinical expertise and staff training, and commissioning.

Advanced therapy treatment centers: precedents \& opportunities

- The successful adoption of RM requires the establishment of specialist innovation niches, such as the proposed network of advanced therapy centers in the UK.

- Hematological and transplant services and existing payment-by-performance risk-sharing schemes represent valuable opportunities for adopting RM.

- The current establishment of a UK proton beam therapy program represents an important precedent for implementing highly disruptive RM therapies in the future.

Institutional readiness for RM

- Institutional Readiness (IR) is useful analytical frame for examining potential clinical sites for cell and gene therapy treatment centers.

- The notion of IR recognizes that adoption is the result of active, ongoing work by a diverse collective of stakeholders.

- Criteria for assessing IR traverse issues relating to regulation and commissioning, staff training and skills base, patient collaboration, bioprocessing and manufacturing.

Future perspective

- It is necessary to plan the long-term implementation of RM over several phases.

- Phase I would involve the identification and establishment of the network of cell and gene therapy centers, using the criteria of IR.

- Phase II would involve the application of the IR analysis to envisage the scale of change needed to move to a much higher order of magnitude in terms of availability.

- Phase III would entail the actual establishment of a wider array of RM providers, and the implementation of the therapy within these providers.

- Determining precisely when and how to move from one phase to another will require ongoing horizon scanning and consultation with diverse stakeholders. 
models; and there is ongoing research into the day-to-day challenges of developing and implementing RM, for example [55,56], which will provide an important reservoir of knowledge.

\section{Financial \& competing interests disclosure}

This paper derives from the REGenableMED project (PI A Webster), funded by the Economic and Social Research Council (ES/L002779/1). J Barry is Chief Clinical Officer at the Cell and Gene Therapy Catapult, which is mentioned in the paper. The authors have no other relevant affiliations or financial involvement with any organization or entity with a financial interest in or financial conflict with the subject matter or materials discussed in the manuscript apart from those disclosed.

No writing assistance was utilized in the production of this manuscript.

\section{Open access}

This work is licensed under the Attribution-NonCommercial-NoDerivatives 4.0 Unported License. To view a copy of this license, visit http://creativecommons.org/licenses/by-nc-nd/4.0/

\section{References}

Papers of special note have been highlighted as: $\bullet$ of interest; $\bullet \bullet$ of considerable interest

1. Webster A. The Global Dynamics of Regenerative Medicine: A Social Science Critique. Palgrave Macmillan, Basingstoke, UK (2013).

2. Mason C, Dunnill P. A brief definition of regenerative medicine. Regen. Med. 3(1), 1-5 (2008).

3. Gardner J, Faulkner A, Mahalatchimy A, Webster A. Are there specific translational challenges in regenerative medicine? Lessons from other fields. Regen. Med. 10(7), 885-895 (2015).

4. Meslin EM, Blasimme A, Cambon-Thomsen A. Mapping the translational science policy 'valley of death'. Clin. Transl. Med. 2, 14 (2013).

5. Dodson BP, Levine AD. Challenges in the translation and commercialization of cell therapies. BMC Biot. 15(1), 70 (2015).

6. House of Lords Science and Technology Committee. Regenerative Medicine. House of Lords, London, UK (2013). www.publications.parliament.uk/pa/ld201314/ldselect/ldsctech/23/23.pdf

7. Thompson K, Foster EP. The Cell Therapy Catapult: growing a UK cell therapy industry generating health and wealth. Stem Cells Dev. 22(Suppl. 1), 35-39 (2013).

8. Regenerative Medicine Expert Group. Building on our own potential: a UK pathway for regenerative medicine (2015). www.gov.uk/government/uploads/system/uploads/attachment_data/file/415919/build-on-potential.pdf

9. House of Commons Science and Technology Committee. Regenerative medicine: fifteenth report of the session 2016-17 (2017). www.publications.parliament.uk/pa/cm201617/cmselect/cmsctech/275/275.pdf

10. Omidvar O, De Grijs M, Castle D, Mittra J, Rosiello A, Tait J. Regenerative medicine: business models, venture capital and the funding gap. Innogen Report (2014). www.innogen.ac.uk/reports/904

11. Advanced Therapies Manufacturing Taskforce, Cell and Gene Therapy Catapult. Advanced therapies manufacturing action plan: retaining and attracting advanced therapies manufacturing in the UK (2016).

www.abpi.org.uk/our-work/mmip/Documents/Advanced-Therapies-Manufacturing-Taskforce-report.pdf

-. A vital, influential report stipulating the need for dedicated cell- and gene-therapy treatment centers.

12. Cell and Gene Therapy Catapult. The Cell and Gene Therapy Catapult UK clinical trials database (2016). https://ct.catapult.org.uk/resources/cell-therapy-catapult-clinical-trials-database/cell-and-gene-therapy-catapult-uk-clinical

13. Karathanasis SK. Regenerative medicine: transforming the drug discovery and development paradigm. Cold Spring Harb. Perspectin. Med. 4(8), a014084 (2014).

14. Mittra J. The New Health Bioeconomy: RerD Policy and Innovation for the Twenty-First Century. Palgrave Macmillan, NY, USA (2016).

15. Mankins J. Technologyreadiness levels: a white paper. Office of Space Access and Technology, NASA, DC, USA (1995).

16. Sauser B, Verma D, Ramirez-Marquez J, Gove R. From TRL to SRL: the concept of systems readiness levels. Conference on Systems Engineering Research. CA, USA, 6-9 April 2006.

17. Gardner J. Understanding innovation and the problem of technology adoption. In: Rethinking the Clinical Gaze: Patient-centred Innovation in Paediatric Neurology. Gardner J (Ed.). Palgrave, Basingstoke, UK, 27-56 (2017).

18. Accelerated Access Review: review of innovative medicines and medical technologies. Crown, London, UK (2016). www.gov.uk/government/uploads/system/uploads/attachment_data/file/565072/AAR_final.pdf

19. Faulkner A. Medical Technology into Healthcare and Society: A Sociology of Devices, Innovation and Governance. Palgrave Macmillan, Basingstoke, UK (2008).

20. May C, Gask L, Atkinson T, Ellis N, Mair F, Esmail A. Resisting and promoting new technologies in clinical practice: the case of telepsychiatry. Soc. Sci. Med. 52(12), 1889-1901 (2001). 
21. Ulucanlar S, Faulkner A, Peirce S, Elwyn G. Technology identity: the role of sociotechnical representations in the adoption of medical devices. Soc. Sci. Med. 98, 95-105 (2013).

22. Abrishami P, Boer A, Horstman K. Understanding the adoption dynamics of medical innovations: affordances of the da Vinci robot in The Netherlands. Soc. Sci. Med. 117, 125-133 (2014).

23. NHS National Institute for Health and Clinical Excellence. Interventional Procedure Guidance 193: treatment of prostate cancer with laparoscopic radical prostatectomy (2006). www.nice.org.uk/guidance/ipg193

24. Cytori Therapuetics Inc. NHS National Innovation Centre Identifies Celution(R) as cost-effective innovative technology for partial breast reconstruction. (2011). http://ir.cytori.com/investor-relations/News/news-details/2011/nhs-national-innovation-centreidentifies-celutionr-as-cost-effective-innovative-technology-for-partial-breast-reconstructi/default.aspx?print=1

25. Gardner J, Higham R, Faulkner A, Webster A. Promissory identities: sociotechnical representations \& innovation in regenerative medicine. Soc. Sci. Med. 174, 70-78 (2017).

26. Sendi PP, Briggs AH. Affordability and cost-effectiveness: decision-making on the cost-effectiveness plane. Health Econ. 10(7), 675-680 (2001).

27. Madden M. Alienating evidence based medicine vs. innovative medical device marketing: a report on the evidence debate at a Wounds conference. Soc. Sci. Med. 74(12), 2046-2052 (2012).

28. Gardner J. Patient-centred medicine and the broad clinical gaze: measuring outcomes in paediatric deep brain stimulation. BioSocieties 12(2), 239-256 (2016).

29. Gardner J. Rethinking the Clinical Gaze: Patient-centred Innovation in Paediatric Neurology Palgrave Macmillan, Basingstoke, UK (2017).

30. May C. Agency and implementation: understanding the embedding of healthcare innovations in practice. Soc. Sci. Med. 78, 26-33 (2013).

-• Provides a detailed account of the dynamics of implementing complex interventions within healthcare settings.

31. Greenhalgh T, Procter R, Wherton J, Sugarhood P, Hinder S, Rouncefield M. What is quality in assisted living technology? The ARCHIE framework for effective telehealth and telecare services. BMC Med. 13(1), 91 (2015).

32. Greenhalgh T, Procter R, Wherton J, Sugarhood P, Shaw S. The organising vision for telehealth and telecare: discourse analysis. $B M J$ Open 2, e001574 (2012).

33. Greenhalgh T, Robert G, Macfarlane F, Bate P, Kyriakidou O. Diffusion of innovations in service organizations: systematic review and recommendations. Milbank Quart. 82(4), 581-629 (2004).

34. May CR. Making sense of technology adoption in healthcare: meso-level considerations. BMC Med. 13(1), 92 (2015).

35. May C, Finch T, Mair F et al. Understanding the implementation of complex interventions in health care: the normalization process model. BMC Health Serv. Res. 7(1), 148 (2007).

36. Corbett MS, Webster A, Hawkins R, Woolacott N. Innovative regenerative medicines in the EU: a better future in evidence? BMC Med. 15(1), 49 (2017).

37. Malik N. Reimbursement and adoption of advanced therapies: the 5-C framework. Regen. Med. 9(5), 573-578 (2014).

38. Abou-El-Enein M, Elsanhoury A, Reinke P. Overcoming challenges facing advanced therapies in the EU market. Cell Stem Cell 19(3), 293-297 (2016).

39. Lowdell MW, Thomas A. The expanding role of the clinical haematologist in the new world of advanced therapy medicinal products. $B r$. J. Haematol. 176(1), 9-15 (2017).

-• A detailed description of why existing hematological services are an important opportunity for implementing cell and gene therapies within existing hospitals.

40. Garrison LP, Towse A, Briggs A et al. Performance-based risk-sharing arrangements - good practices for design, implementation, and evaluation: report of the ISPOR Good Practices for Performance-based Risk-Sharing Arrangements Task Force. Value Health 16(5), 703-719 (2013).

41. Gardner J, Webster A. The social management of biomedical novelty: facilitating translation in regenerative medicine. Soc. Sci. Med. 156, 90-97 (2016).

- Provides a description of innovation niches in regenerative medicine, and how they are constructed via stakeholder negotiation.

42. Schot J, Geels FW. Niches in evolutionary theories of technical change. J. Evol. Econ. 17(5), 605-622 (2007).

43. Videregen Ltd. Impact Report May 2017. Videregen Ltd, Liverpool, UK (2017).

44. Malik N. Pay-for-performance pricing for a breakthrough heart drug: learnings for cell and gene therapies. Regen. Med. 11(3), 225-227 (2016).

45. National Services Division. Risk share. NHS National Services Scotland, Edinburgh, UK (2017).

46. Espin J, Rovira J, Garcia L. Experiences and impact of European risk-sharing schemes focusing on oncology medicines. escuela andaluza de salud publica, Granada, Spain (2011). 
47. Regalado A. Gene-therapy cure has money-back guarantee. MIT technology review (2016). www.technologyreview.com/s/602113/gene-therapy-cure-has-money-back-guarantee/

48. NHS England. Proton beam therapy. www.england.nhs.uk/commissioning/spec-services/highly-spec-services/pbt/

49. Department of Health. Government commits $£ 250$ million for innovative cancer treatment to save lives and reduce side effects (2013). www.gov.uk/government/news/government-commits-250-million-for-innovative-cancer-treatment-to-save-lives-and-reduce-sideeffects

50. Ocloo J, Matthews R. From tokenism to empowerment: progressing patient and public involvement in healthcare improvement. $B M J$ Quality \& Safety 25(8), 626-632 (2016).

51. Bate P, Robert G. Experience-based design: from redesigning the system around the patient to co-designing services with the patient. Qual. Saf. Health Care 15(5), 307-310 (2006).

52. Bate P, Robert G. Bringing User Experience to Healthcare Improvement: The Concepts, Methods and Practices of Experience-based Design. Radcliffe Publishing Ltd, Oxford, UK (2007).

53. Gardner J, Warren N, Carter A, Paul M, Dominguez. DBS as a 'Technological Fix' or a 'Regime of Care'? Recognising the importance of narrative identity in neurosurgical services. AJOB Neuro 8(3), 192-194 (2017).

54. Murray E, Treweek S, Pope C et al. Normalisation process theory: a framework for developing, evaluating and implementing complex interventions. BMC Med. 8(1), 63 (2010).

55. Addison C. Bench, bedside, boardroom: negotiating translational gene therapy. New Gen. Soc. 36(1), 22-42 (2017).

56. Ziya S, Medcalf N, El Haj A, Wright K. Facilitating the operational readiness of the NHS for the in-house manufacture and delivery of autologous cell therapy. Cytology 19(5), S147 (2017). 